\title{
BMJ Open Under reporting of road traffic injuries in the district of Kandy, Sri Lanka
}

\author{
Nithershini Periyasamy, ${ }^{1}$ Catherine A Lynch, ${ }^{2}$ Samath D Dharmaratne, ${ }^{3,4}$ \\ DB Nugegoda, ${ }^{5}$ Truls Østbye ${ }^{6}$
}

To cite: Periyasamy N, Lynch CA, Dharmaratne SD, et al. Under reporting of road traffic injuries in the district of Kandy, Sri Lanka. BMJ Open 2013;3:e003640. doi:10.1136/bmjopen-2013003640

- Prepublication history for this paper is available online To view these files please visit the journal online (http://dx.doi.org/10.1136/ bmjopen-2013-003640).

Received 22 July 2013 Revised 30 September 2013 Accepted 11 October 2013

\section{CrossMark}

For numbered affiliations see end of article.

Correspondence to Dr Nithershini Periyasamy; nithershini@yahoo.co.in

\section{ABSTRACT}

Objectives: To conduct a community survey to estimate the degree to which road traffic injuries (RTIs) are under reported and to compare the characteristics of RTI reported to the police to those not reported.

Design: A cross-sectional population-based study. Setting: Kandy district, Sri Lanka.

Participants: RTIs and deaths during the preceding 12 months were identified through a community-based cross-sectional survey with a sample size of 3080 households. A stratified multistage cluster sampling with population proportion to size was used. 'Events reported' to the police were cross checked against events in the police records of the given or adjacent police stations, and either were 'Events found' or 'Not found'. 'Under reported' included those 'Not reported' and those reported but 'Not found' in the police dataset.

Results: Information about 11724 persons were obtained from 3080 households, identifying 149 persons who suffered an RTI. Of these, $57 \%$ were 'Events reported', and of these $43.6 \%(n=65)$ were Events found' in police records $(95 \% \mathrm{Cl}, 36.0$ to 51.6). There were 42 events 'Not reported' to police while an additional 7 were 'Not found' in the police records of the given police station. Although they were claimed to have been reported to the police, $33 \%$ ( $95 \% \mathrm{Cl} 25.8$ to 40.7) were 'Under reported'. There were significant differences in age $(p=0.02)$, family income $(p<0.001)$, road user type $(p=0.001)$, injury severity $(p<0.001)$ and injury category $(p=0.01)$ between 'Events found' in the police records and 'Under reported' events.

Conclusions: In the Kandy district, $33 \%$ of RTIs were 'under reported'. These findings could be used as evidence for policy planning to prevent RTIs, and highlights the need for a nation-wide community-based survey to determine the true rates of RTI for a better understanding of the reasons for under reporting.

\section{INTRODUCTION}

Road traffic crashes are of global concern, due to the rising trends of deaths and disability following road traffic crashes. Such crashes have also caused a huge burden on the economy and healthcare services. Current interventions for this problem are

\section{Strengths and limitations of this study}

This is a community-based survey with a large sample size.

- By using the community survey to capture the road traffic injuries, we were able to capture a representative sample of the study area with a $100 \%$ response rate.

- This study is limited by self-report and recall bias.

- The proportion of under reported events may not be generalisable to the national level due to socioeconomic, education, and variations in the accessibility to the police reporting system.

sporadic, uncoordinated and ineffective in many countries. ${ }^{1}$ The WHO estimates that, worldwide, between 20 million and 50 million people are injured or disabled each year in road traffic crashes. ${ }^{2}$ Since 1990 , road traffic death rates in low-income and middle-income countries (LMIC) have increased substantially and are predicted to rise on average by over $80 \%$ in LMIC while declining by almost $30 \%$ in high-income countries by $2020 .^{2}$ Reducing road deaths and injuries in developing countries is crucial not only for public health reasons, but also because road crashes place a heavy burden on the national, regional and household economies. The economic cost of road traffic injuries (RTIs) is estimated to be US $\$ 518$ billion/annum, with US\$100 billion from developing countries alone. This is twice the annual amount of development assistance to developing countries. ${ }^{2}$

\section{UNDER REPORTING}

Under reporting or failure to report the RTI in official statistics has often raised the concern about the inaccuracy of statistics and its effect on road safety policy-making and planning. The World Health Report emphasises the need for good and complete data and scientific approaches in the prevention and control of RTIs. ${ }^{2}$ Elvick and Mysen $^{3}$ 
stated that the true number of road traffic crashes is unknown, and virtually all studies of road crashes including more than one type of data compare just two sources, most commonly police and hospital records, and the level of completeness of these datasets is limited. These two sources do not capture those who do not go to the hospital or to the police, resulting in a further underestimation of under reporting. It is said that accurate death and injury rates would best be generated through community-based studies. ${ }^{4}$

\section{STATUS IN SRI LANKA}

In Sri Lanka, road traffic deaths have been increasing steadily and are now one of the major causes of morbidity and mortality in the country. ${ }^{5} 6$ According to the National Police data, the annual incidence of RTIs and deaths has reached epidemic proportions, with more than 2000 deaths and more than 20000 injuries annually. $^{7}$ The number of motor vehicles in Sri Lanka increased from 0.8 to 3.9 million between 1990 and 2010 in Sri Lanka. ${ }^{7}$ Recently, a policy of 'on the spot' insurance payments for damages resulting from crashes have allowed motorists to bypass the reporting of incidents to the police, further worsening the under reporting situation. At present, Sri Lanka's national data on RTIs are based on police statistics, and most of the available statistical reports and studies until now have been based on either police data or hospital records. In 19771981, a study in Colombo, Sri Lanka using police and medical data found $77 \%$ that hospitalised patients were not identified in the police records, suggesting that many RTIs requiring admission to a hospital were not reported to the police. ${ }^{9}$ While accurate death and injury rates may best be generated through community-based studies; such studies are expensive and difficult to conduct, especially in developing countries. ${ }^{4} 10$

There have been no community-based surveys assessing the under reporting of RTI in Sri Lanka until now date. The objective of this study was to conduct such a survey to estimate the degree to which RTIs are under reported and to compare the characteristics of RTI reported to the police to those not reported.

\section{METHODS}

The study was carried out in the Kandy district, in the Central Province of Sri Lanka, with a total population of 1279028 according to the 2001 census. ${ }^{11}$ Of this population, $12.1 \%$ was urban while $80.6 \%$ was rural and $7.3 \%$ was estate (a tea or rubber plantation community). The ethnic distribution of the district comprised $74.2 \%$ Sinhalese, $12.7 \%$ Tamils, $12.3 \%$ Muslims and $0.8 \%$ others. ${ }^{11}$ The results reported in this article are part of a larger study. ${ }^{12}$

Under reporting of RTI was estimated from the results of a community-based cross-sectional study being cross checked with the police records. The community-based survey was conducted using stratified multistage cluster sampling of 77 clusters utilising population proportion to size sampling in the Kandy district. The people in selected households were interviewed using an intervieweradministered structured questionnaire. This part of the study identified road traffic injury or death (the event) using an operational definition thus: any injury to a road user (pedestrian, pedal cyclist, motorcyclist, vehicle driver or passenger of a vehicle) following contact with a moving vehicle (includes a motorcycle, heavy vehicle, bicycle or cart) or due to the sudden breakdown of a vehicle (engine failure, break failure, bicycle chain slip, etc.) while moving, or a fall from a moving vehicle when travelling on a road, lane and path and a person killed during a road traffic crash, or within 30 days as a result of a crash is referred to as a road traffic death. ${ }^{2}$ Traffic police of Sri Lanka use a similar description of road traffic crashes that are to be reported to the police. ${ }^{13}$ Events claimed to be reported during the community survey for the period 1 January 2007 to 31st December 2007 (hereafter referred as Events Reported) were cross checked with traffic police records.

Information on individuals in the selected households was obtained from the household spokesman including information on past RTI events. Information was obtained about individuals who sustained an injury or death due to a road traffic crash during the preceding 12 months through a detailed questionnaire. The following crash details were used to locate the events in the police database: age, name, address, date and place of occurrence, place of reporting, severity of injury and crash registration number if available (box 1).

RTI victims who stated in the survey that their crashes had not been reported to the police were assigned as 'Not Reported'. Those who stated in the survey that they had reported the event to the police (Event Reported) were then cross checked with the local police records of the given or adjacent police stations by the principal investigator (NP). Those events identified during the survey that were supposedly reported to the police but that were not documented in the police records of the given police station were assigned as 'Not Found', while those allegedly reported to the police in the survey and that were confirmed in police records were categorised

\section{Box 1 Definition of severity of injury}

Grievous injuries mean:

- Loss of a distinct organ

- Serious disfigurement

- Fracture of any bone

- Severe laceration, or injury to any internal organs

- Severe burn affecting more than $5 \%$ of the body surface

Non-Grievous injuries mean:

All other injuries (sprain, bruising, abrasions)

Fatal injuries mean:

Death within 30 days of injury 


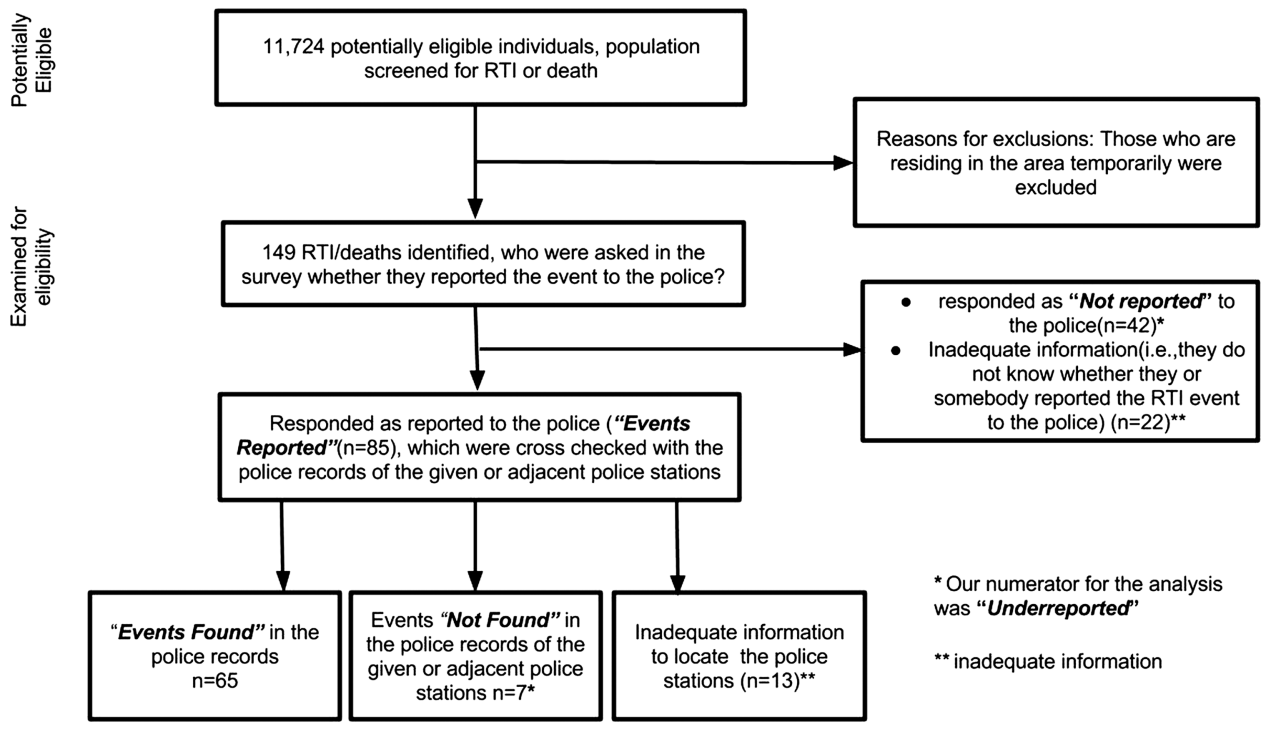

Figure 1 Description of the derivation of the numerator 'Under reported'.

as Events Found'. The 'Under reported' category includes events that were 'Not Reported' and 'Not Found' in the police documents (figure 1).

Checks for survey completeness and quality assurance were performed daily by the principal investigator (NP). Data were entered into a database, EPI Info V.6.0 (software developed by Centers for Disease Control and Prevention, Atlanta). Data were analysed with the Statistical Packages for Social Science (SPSS) V.13.0 (SPSS Inc, Chicago, Illinois, USA). RTI events with inadequate information were excluded from the comparative analysis. For the calculation of 'Under reported' events in a first analysis, RTI events with inadequate information (those who do not remember whether they reported the injury event to the police $(n=22)$, and those who stated as reported to the police, with inadequate information to locate the police stations $(n=13))$ to cross check claims were excluded. Then, data with inadequate information were included and further analysis was conducted in order to report the best possible and worst possible reporting scenarios. The best possible estimates included all cases with the inadequate information as if they were reported to the police appropriately while the worst possible estimates were treated as if they were not reported to the police.

Family income of 'Events found' and 'Under reported' was categorised into four quintiles, and used for the comparison of wealth quintiles between two groups. 'Under reported' RTI is displayed as percentage with 95\% CI. $\chi^{2}$ Test or Fisher's exact test were used for the comparative analysis. For all analyses, the level of significance was determined to be $\mathrm{p} \leq 0.05$.

\section{RESULTS}

The population-based survey obtained information about 11724 people and adequately represented the district population. The mean age was 26.8 ( $\mathrm{SD}=18.7,2-98$ years; table 1). One hundred and forty-nine people were identified including 16 deaths due to RTIs in the preceding 12 months. The incidence of RTI was estimated at 12.7/ 1000 population (95\% CI 12.5 to 12.9$).{ }^{12}$ Of these 149 RTI events elicited in the survey, 85 had responded as 'Events Reported' to the police, 42 had responded as 'Not Reported' to the police, and 22 had responded as 'Do not know' (inadequate information; figure 1). By cross checking with the police records, 65 of 85 RTIs were 'Events Found' in the police dataset of the given or adjacent police station leading to overall reporting of only $43.6 \%$ (65 of 149) (95\% CI 36.0 to 51.6).

Table 1 Demographic comparison of the Kandy district data with the community survey

\begin{tabular}{llll}
\hline & $\begin{array}{l}\text { District data } \\
(\mathbf{2 0 0 1 )} \\
\mathbf{n = 1 2 7 9 ~ 0 2 8 \%}\end{array}$ & $\begin{array}{l}\text { Community } \\
\text { survey (2008) } \\
\mathbf{n = 1 1 7 2 4 \%}\end{array}$ & $\begin{array}{l}\text { RTI } \\
\text { victims } \\
\mathbf{n}=\mathbf{1 4 9 \%}\end{array}$ \\
\hline Age in years & & & \\
$<1-24$ & 45.9 & 45.4 & 16.8 \\
$25-49$ & 35.0 & 41.6 & 58.4 \\
$\geq 50$ & 19.1 & 12.8 & 24.8 \\
Sex & & & \\
Male & 48.9 & 49.9 & 77.9 \\
Female & 51.1 & 50.1 & 22.1 \\
Ethnicity & & & \\
Sinhala & 74.0 & 65.0 & 67.1 \\
Tamil & 12.3 & 12.3 & 12.1 \\
Muslim & 13.3 & 22.4 & 19.5 \\
Malay & 0.1 & 0.1 & 1.3 \\
Burger & 0.2 & 0.2 & 0.0 \\
Others & 0.1 & 0.02 & 0.0 \\
Total & 100.0 & 100.0 & 100.0 \\
\hline Source: National data are from the census of population and \\
housing, 2001, Sri Lanka: District report. Kandy: Department of \\
census and statistics 2001. \\
RTI, road traffic injuries.
\end{tabular}


In the best-case scenario where all cases with inadequate reporting information were actually reported to the police, the 'Under reported' proportion was 33\% $((49 / 149)$ (95\% CI 25.8 to 40.7)). Yet in the worst-case scenario where all cases with inadequate reporting information were not reported to the police, the 'Under reported' proportion was $56.3 \% \quad((84 / 149) \quad(95 \%$ CI 48.3 to 64.2$)$ ). If the cases with inadequate information were excluded completely from the analysis, then the under reporting was $42.3 \%$ ((49/114) $(95 \%$ CI 33.1 to 51.4)). Therefore, the RTI case under reporting is somewhere between $33.0-56.3 \%$.

The RTI victims were mostly male $(78.9 \%, \mathrm{n}=116)$ with a mean age of 38.5 years ( $\mathrm{SD}=16.8,3-95$ years), and most were in the productive age group of 25-49 years (tables 2 and 3). By comparing the 'Under reported' and 'Events Found' groups, the 'Under reported' group was found to be significantly more likely to be of productive ages (25-49 years; $\mathrm{p}=0.02)$ and to have had non-grievous or non-fatal injuries $(\mathrm{p}<0.001,0.01)$. A comparison of the wealth quintiles among the 'Under reported' and 'Events Found' groups showed significant proportion of 'Under reported' in the richest wealth quintile $(p<0.001)$. While the road users were further grouped into motor vehicle occupants (drivers and passengers) and vulnerable road users (pedestrians/twowheeler users), in comparison pedestrians/two-wheeler users had a significantly higher proportion of 'Under reported' ( $\mathrm{p}=0.03$ ) to the police (table 4 ).

There were 16 deaths identified during the survey. Of these, $13(81.2 \%)$ were among 'Events Found'. Two of
16 deaths $(12.5 \%)$ from the survey were 'Not Reported' to the police while one had inadequate information to cross check with police records.

When the 'Not Reported' $(n=42)$ were further explored, 26.2\% $\quad(n=12)$ cited the reason for nonreporting the crash was their own fault (table 5). In less than one-third $(28.6 \%)$ of the events, they were not willing to give any reason for not reporting.

\section{DISCUSSION}

This study was the first community-based survey conducted in Sri Lanka to estimate the under reporting of RTIs. RTI under reporting in the district of Kandy was estimated to be between $33.0 \%$ and $56.3 \%$. Some studies have cited the RTI under reporting proportions to be between $18 \%$ and $76 \%^{10}{ }^{14-16}$ but these were comparisons of hospital-based surveys which usually exclude prehospital deaths and less-severe injuries. In this study, under reporting was high in the productive age (2549 years) group, and among vulnerable road users (pedestrians and two-wheeler users). Nearly half (41.2\%) of the non-fatal injuries were 'Under reported', with only $81.2 \%$ of the fatal injuries being reported. Of the injured road users in the highest income quintile, not a single event was reported while in the lowest income quintile, every incident was reported to the police.

Demographic factors age group, family income, injury categories (fatal/non-fatal), severity of injuries and type of road users were significantly associated with under

\begin{tabular}{|c|c|c|c|c|}
\hline & 'Events found' \%(n) & 'Under reported' \%(n) & Inadequate information \%(n) & Total \%(n) \\
\hline \multicolumn{5}{|l|}{ Age in years } \\
\hline$<1-24$ & 60.0 & $28.0(7)$ & $12.0(3)$ & $100.0(25)$ \\
\hline $25-49$ & $34.5(30)$ & $40.2(35)$ & 25.3 (22) & $100.0(87)$ \\
\hline$\geq 50$ & $54.1(20)$ & $18.9(7)$ & $27.0(10)$ & $100.0(37)$ \\
\hline \multicolumn{5}{|l|}{$\operatorname{Sex}$} \\
\hline Male & $43.1(50)$ & 33.6 (39) & $23.3(27)$ & 100.0 \\
\hline Female & $45.5(15)$ & $30.3(10)$ & $24.2(8)$ & $100.0(33)$ \\
\hline \multicolumn{5}{|l|}{ Sector } \\
\hline Urban & $42.9(6)$ & $42.9(6)$ & $14.3(2)$ & $100.0(14)$ \\
\hline Rural & $40.8(51)$ & $32.8(41)$ & 26.4 (33) & 100.0 \\
\hline Estate & $80.0(8)$ & $20.0(2)$ & $0.0(0)$ & $100.0(10)$ \\
\hline \multicolumn{5}{|l|}{ Ethnicity } \\
\hline Sinhala & $37.0(37)$ & $36.0(36)$ & $27.0(27)$ & $100.0(100$ \\
\hline Tamil & $72.2(13)$ & $22.2(4)$ & $5.6(1)$ & 100.0 \\
\hline Muslim & $48.3(14)$ & $27.6(8)$ & $24.1(7)$ & $100.0(29)$ \\
\hline Malay & 50.0 (1) & $50.0(1)$ & $0.0(0)$ & $100.0(2)$ \\
\hline \multicolumn{5}{|l|}{ Family income } \\
\hline 1st quintile & $100.0(47)$ & $0.0(0)$ & $0.0(0)$ & $100.0(47)$ \\
\hline 2nd quintile & $37.0(10)$ & $63.0(17)$ & $0.0(0)$ & $100.0(27)$ \\
\hline 3rd quintile & $13.3(8)$ & $40.0(24)$ & $46.7(28)$ & $100.0(60)$ \\
\hline 4th quintile & $0.0(0)$ & $53.3(8)$ & $46.7(7)$ & $100.0(15)$ \\
\hline Total & $43.6(65)$ & $32.9(49)$ & 23.5 (35) & 100.0 \\
\hline
\end{tabular}


Table 3 Comparing 'Events found' and 'Under reported'

\begin{tabular}{|c|c|c|c|c|}
\hline & 'Events found' \%(n) & ‘Under reported’ \%(n) & Inadequate information \%(n) & Total \%(n) \\
\hline \multicolumn{5}{|l|}{ Type of road users } \\
\hline Driver & $56.0(14)$ & $24.0(6)$ & $20.0(5)$ & $100.0(25)$ \\
\hline Passengers & $50.0(20)$ & $25.0(10)$ & $25.0(10)$ & $100.0(40)$ \\
\hline Pedestrians & $51.0(26)$ & $29.4(15)$ & $19.6(10)$ & $100.0(51)$ \\
\hline Motorcyclists & $12.0(3)$ & $56.0(14)$ & $32.0(8)$ & $100.0(25)$ \\
\hline Bicyclists & $25.0(2)$ & $50.0(4)$ & $25.0(2)$ & $100.0(8)$ \\
\hline \multicolumn{5}{|l|}{ Type of crash } \\
\hline Vehicle-vehicle & $41.7(20)$ & $37.5(18)$ & $20.8(10)$ & $100.0(48)$ \\
\hline Vehicle-passenger & $50.0(10)$ & $30.0(6)$ & $20.0(4)$ & $100.0(20)$ \\
\hline Vehicle-pedestrian & $50.9(28)$ & $27.3(15)$ & $21.8(12)$ & $100.0(55)$ \\
\hline Vehicles-road structure & $30.0(4)$ & $30.0(6)$ & $40.0(8)$ & $100.0(20)$ \\
\hline Other & $16.7(1)$ & $66.7(4)$ & $16.7(1)$ & $100.0(20)$ \\
\hline \multicolumn{5}{|l|}{ Injury severity } \\
\hline Fatal & $81.2(13)$ & $12.5(2)$ & $6.3(1)$ & $100.0(16)$ \\
\hline Grievous & $61.3(30)$ & $22.4(11)$ & $16.3(8)$ & $100.0(49)$ \\
\hline Non-grievous & $26.2(22)$ & $42.9(36)$ & $30.9(26)$ & $100.0(84)$ \\
\hline Total & $43.6(65)$ & 32.9 (49) & $23.5(35)$ & 100.0 (149) \\
\hline
\end{tabular}

reporting. Non-fatal and non-grievous injuries were significantly 'Under reported', most likely due to a poor understanding of the importance of reporting by the injured road users. Economically productive aged (25-49 years) individuals and vulnerable road users (pedestrians, two-wheeler users) significantly 'Under reported', most likely because they considered it as a waste of time and money and because it was logistically inconvenient to report the event. This was evident from the significant number of 'Under reported' events by the victims in the highest-income group.

Although Sri Lankan law mandates the reporting of all road traffic crashes to the nearest police station within $24 \mathrm{~h}$, the under reporting of RTIs was between $33 \%$ and $56.3 \%$ in this study.

Table 4 Differences between 'Events found' and 'Under reported'

\begin{tabular}{|c|c|c|c|c|}
\hline & 'Events found' \% (n) & ‘Under reported’ \% (n) & Total \% (n) & p Value \\
\hline \multicolumn{5}{|l|}{ Age in years } \\
\hline$<1-24$ & $68.2(15)$ & $31.8(7)$ & $19.3(22)$ & \multirow{3}{*}{$\begin{array}{l}p=0.02 \\
d f=2\end{array}$} \\
\hline $25-49$ & $34.5(30)$ & $40.2(35)$ & $57.0(65)$ & \\
\hline$\leq 50$ & $54.1(20)$ & $18.9(7)$ & $23.7(27)$ & \\
\hline \multicolumn{5}{|l|}{ Family income } \\
\hline 1st quintile & $100.0(47)$ & $0.0(0)$ & $41.2(47)$ & \multirow{4}{*}{$\begin{array}{l}\mathrm{p}<0.001 \\
\mathrm{df}=3\end{array}$} \\
\hline 2nd quintile & $37.0(10)$ & $63.0(17)$ & $23.6(27)$ & \\
\hline 3rd quintile & $25.0(08)$ & $75.0(24)$ & $28.1(32)$ & \\
\hline 4th quintile & $0.0(0)$ & $100.0(8)$ & $7.0(8)$ & \\
\hline \multicolumn{5}{|l|}{ Road users } \\
\hline Driver & $56.0(14)$ & $24.0(6)$ & $20(17.5)$ & \multirow{4}{*}{$\begin{array}{l}p=0.01 \\
d f=3\end{array}$} \\
\hline Passenger & $50.0(20)$ & $25.0(10)$ & $30(26.3)$ & \\
\hline Pedestrians & $51.0(26)$ & $29.4(15)$ & $41(36.0)$ & \\
\hline Two-wheeler users & $15.1(5)$ & $54.5(18)$ & $23(20.2)$ & \\
\hline \multicolumn{5}{|l|}{ Injury severity } \\
\hline Grievous/fatal & $37.7(43)$ & $11.4(13)$ & $49.1(56)$ & \multirow{2}{*}{$\begin{array}{l}\mathrm{p}<0.001 \\
\mathrm{df}=1\end{array}$} \\
\hline Non-grievous & $19.3(22)$ & $31.6(36)$ & $50.9(58)$ & \\
\hline \multicolumn{5}{|l|}{ Injury category } \\
\hline Fatal & $11.4(13)$ & $1.8(2)$ & $13.1(15)$ & \multirow{2}{*}{$\begin{array}{l}p=0.01 \\
d f=1\end{array}$} \\
\hline Non-fatal & $45.6(52)$ & $41.2(47)$ & $86.8(99)$ & \\
\hline \multicolumn{5}{|l|}{ Road user category } \\
\hline Vulnerable road users* & $27.2(31)$ & $29.0(33)$ & $56.1(64)$ & \multirow{4}{*}{$\begin{array}{l}p=0.03 \\
d f=1\end{array}$} \\
\hline Motor vehicle & $30.0(34)$ & $14.0(16)$ & $43.9(50)$ & \\
\hline occupants† & & & & \\
\hline Total & $57.0(65)$ & $43.0(49)$ & $100.0(114)$ & \\
\hline
\end{tabular}


Table 5 Reasons events were 'Not reported' to the police

\begin{tabular}{ll}
\hline Reasons for 'Not reported' & percentage $\mathbf{( n )}$ \\
\hline Considered due to their own mistake & $26.2(11)$ \\
Mildly injured & $9.5(4)$ \\
Negotiated with both parties & $11.9(5)$ \\
Not considered as a crash & $7.1(3)$ \\
Others* & $16 .(7)$ \\
No answer & $28.6(12)$ \\
Total & $(100.0) 42$ \\
\hline
\end{tabular}

*Others include consequences for the opposite party, not locating the vehicle, intimidation and difficult in accessing the police station.

People were generally reluctant to report injuries to the police to avoid the consequences for the crash if they were at fault. However, if the injured were admitted to a government hospital, then the injury would be reported to the hospital police post for medicolegal examination and also to the police statistics. Private vehicle owners were discouraged against reporting events to the police in order to avoid penalties to their income, or for fear of legal action due to vehicle or driver liability. ${ }^{17}$ Others avoided the legal procedures, the reporting procedures required and the time commitment required for reporting. Crash reporting is not compulsory for insurance claims and policies may in fact encourage non-reporting; the 'On the Spot' insurance policy was in place during this study period, and there also was a $10 \%$ reduction in premium for no claims being filed in the past year. Another important reason for not reporting was negotiation and financial settlement between the parties either by compensation or by supporting the entire healthcare cost of the injury (taking the injured to the hospital, follow-up clinics, being a caretaker in the hospital, etc) or because a less severe injury led them not to bother to report the event to police. To improve the reporting system after the RTIs, we must consider the injured road users' perception of reporting as unnecessary, timeconsuming as well as the difficult reporting procedures.

\section{IMPACT ON HEALTH}

Allocation of limited resources and policy planning may be biased due to the under reporting of RTI. The Global Burden of Disease has shown that RTIs has moved from the 10th to 8th leading cause of death in 2010. ${ }^{18}$ Predictions suggest that RTI will be the third leading cause disability by $2020 .{ }^{19}$ Unreliable data in Sri Lanka, as in other LMICs, will most likely lead to insufficient funding to address the impact of this important global public health problem.

\section{LIMITATIONS}

The results of this study may not generalise to the national level due to socioeconomic and education variations in the population and variations in the accessibility to the police reporting system. Our community-based survey data may also have been limited by self-report and recall biases given the 1 year time frame chosen for recall. Owing to the resource limitation and feasibility issues, 'Not Reported' and 'Not Found' events were not checked against data in other police stations in the country. All road traffic crashes would not have resulted in an injury; therefore, restricting our study to only RTIs is not ideal for understanding the true under reporting caused by RTC. Future studies estimating under reporting should consider all RTCs and RTIs. Our study highlights the need for a nationwide community-based survey to determine the true rates of RTI for policy planning and for better understanding the reasons for under reporting.

\section{CONCLUSION}

Under reporting between $33 \%$ and $56 \%$ in the district of Kandy demonstrates that the real burden of traffic injury was underestimated. Under reporting was most pronounced among non-fatal, non-severe injuries and among the high-income group and middle-aged vulnerable road users. Under reporting was most likely influenced by the human tendency to avoid legal procedures and to avoid wasting time or money by reporting the event. This study highlights the need to increase population education on the importance of reporting, and to create a favourable environment to improve reporting in order to have complete and reliable data for effective and efficient policy planning.

\section{Author affiliations}

${ }^{1}$ Postdoctoral Visiting Scholar, Duke Global Health Institute, Duke University, Durham, North Carolina, USA

${ }^{2}$ Division of Emergency Medicine, Duke School of Medicine, Duke Global Health Institute, Duke University Medical Center, Durham, North Carolina, USA ${ }^{3}$ Department of Community Medicine, Faculty of Medicine, University of Peradeniya, Peradeniya, Sri Lanka

${ }^{4}$ Department of Global Health, School of Public Health, Institute for Health Metrics and Evaluation, University of Washington, Seattle, Washington, USA

${ }^{5}$ Department of Community Medicine, Faculty of Medicine, University of Rajarata, Sri Lanka

${ }^{6}$ Duke School of Medicine, Duke Global Health Institute, Duke University Medical Center, Durham, North Carolina, USA

Acknowledgements We would like to thank the Provincial Director of Health Services, Central Province, Regional Director of Health Services, Kandy, all Medical Officers of Health and all Superintendents of Estates in the Kandy district for the approval and support provided. Special thanks go to the Public Health Midwives who collected the data, the Officers in Charge and the police officers of Traffic divisions for their support and assistance during the study. All injured road users are remembered with gratitude for their participation in the study.

Contributors NP designed the study plan, data collection tools, collected the data, monitored the data collection for the whole study, wrote the statistical analysis plan, cleaned and analysed the data, as well as drafted and revised the paper. She is the guarantor. CAL analysed and interpreted the data, drafted and revised the paper critically and also approved the final version. SDD initiated and designed the study plan, data collection tools, monitored the data collection for the whole study, revised the paper critically and approved the final version. DBN designed the study plan and data collection tools, monitored the data collection for the whole study, interpreted the data, revised the paper critically and approved the final version. Tø interpreted the data, revised the paper critically and approved the final version to be published. 
Funding This study was partially funded by the Health Emergency and Disaster Management and Treatment Center (HEDMaTC) at the faculty of Medicine, University of Peradeniya.

Competing interests None.

Patient consent Obtained.

Ethics approval Ethical approval was obtained from the Ethical Review Committee of the Faculty of Medicine, University of Peradeniya, Sri Lanka. Pretesting of the questionnaire was carried out in an adjoining area to the survey area (the Matale Medical Officer of Health area).

Provenance and peer review Not commissioned; externally peer reviewed.

Data sharing statement No additional data are available.

Open Access This is an Open Access article distributed in accordance with the Creative Commons Attribution Non Commercial (CC BY-NC 3.0) license, which permits others to distribute, remix, adapt, build upon this work noncommercially, and license their derivative works on different terms, provided the original work is properly cited and the use is non-commercial. See: http:// creativecommons.org/licenses/by-nc/3.0/

\section{REFERENCES}

1. Odera W. Africa's Epidemic of Road Traffic Injuries: trends, Risk factors, and Stratergies for Improvement. A paper presentation on the occasion of World Health Day, 2004 at The Harvard center for population and development studies Diseases and Related Health Problems. 10th edn. 2004:1:1018-19.

2. Peden $M$, Scurfield $\mathrm{R}$, Sleet $\mathrm{D}$, et al. World report on road traffic injury prevention. Geneva: World Health Organization, 2004.

3. Elvik R, Mysen AB. Incomplete Accident Reporting: Meta-anlaysis of Studies Made in 13 Countries. Component. 1999. Report No.: $00771222,1999$.

4. Sethi D, Habibula S, McGee K, et al. Guidelines for conducting community surveys on injuries and violence. Switzerland: World Health Organization, 2004.
5. Dharmaratne S, Ameratunga S. N(729-730. Road traffic injuries in Sri Lanka: a call to action. JCPSP 2004;14:729-30.

6. SriLanka. Annual health bulletin 2007. 1st edn. Sri Lanka: Ministry of Health, 2007.

7. Traffic Statistics. Sri Lanka: Traffic Police, Sri Lanka Police; 2010. http://www.police.lk/index.php/traffic-police (accessed 2012).

8. Somasundaraswaran AK. Accident Statistics in Sri Lanka. IATSSS Research 2006;30:115-17.

9. Sayer I, Hitchcock R. An analysis of police and medical road accident data: Sri Lanka 1977-1981. England: Transport and Road Research Laboratory, 1984

10. Razzak JA, Luby SP. Estimating deaths and injuries due to road traffic accidents in Karachi, Pakistan, through the capture-recapture method. Int J Epidemiol 1998;27:866-70.

11. Census of Population and Housing, 2001, Sri Lanka: District report. Kandy: Department of Census and Statistics, 2005.

12. Nithershini P, Nugegoda DB, Dharmaratne SD. Incidence of road traffic injuries (RTI) in the district of Kandy, Sri Lanka, and its economic impact to the households and to the state [MD Thesis] Sri Lanka: Community Medicine, Post Graduate Institute of Medicine, University of Colombo, 2011

13. Road Traffic Accidents [database on the Internet]. http://www.police. Ik/index.php/traffic-police/112

14. Social and Economic consequences of Road traffic Injury in Europe. Brussels: European Transport Safety Council; 2007. http://www.etsc. eu/documents/Social\%20and\%20economic\%20consequences\% 20 of\%20road\%20traffic\%20injury\%20in\%20Europe.pdf

15. Salifu M, Ackaah W. Under-reporting of Road Traffic Crash data in Ghana. 4th IRTAD Conference, Seoul, Korea, 2009.

16. Loo BPY, Tsui KL. Factors affecting the likelihood of reporting road crashes resulting in medical treatment to the police. Inj Prev 2007;13:186-9.

17. Dharmaratne SD, Stevenson M. Public road transport crashes in a low income country. Inj Prev 2006;12:417-20.

18. Global Burden of Disease Study 2010 (GBD 2010) Results by Risk Factor 1990-2010. Institute for Health Metrics and Evaluation (IHME) 2012 [cited 2013]; http://www.healthmetricsandevaluation.org/gbd/ visualizations/gbd-arrow-diagram

19. Murray JLC, Lopez AD Alternative projections of mortality and disability by cause 1990-2020: global burden of disease study. Lancet 1997:349:1498-504. 